\title{
Spruce and broadleaved trees pollen percentages and PAR values in the European part of Russia: 9 years of pollen trap monitoring implemented to the fossil data
}

\author{
Maria Nosova $^{1}$, Elena Severova ${ }^{2}$, Olga Volkova ${ }^{2}$ \\ 'Main Botanical Garden RAS, 127276, Botanicheskaya, 4, Moscow, Russia, \\ e-mail: mashanosova@mail.ru \\ ${ }^{2}$ Higher Plants Department, Leninskie Gory, 1, 12, 119234, Moscow, Rusia, Moscow State University
}

Received: 22 April 2017/Accepted: 01 June 2017

\begin{abstract}
Central European Russia are presented. We discuss some implementations of modern pollen data to the interpretation of fossil distribution for Picea and broadleaved trees pollen.
\end{abstract}

Keywords: modern pollen deposition, pollen monitoring, Tauber traps, Holocene, Picea, broadleaved trees

\section{Introduction}

Picea abies s.l. and broadleaved trees (Quercus robur, Tilia cordata, Ulmus glabra, U. scabra, Acer platanoides and Fraxinus excelsior) are the important forest-forming taxa in the Central and North-Western part of the European Russia (NW ER). Complex forests consisting of spruce and broadleaved species in various combinations (and succession series) represented primary vegetation (before the beginning of large-scale human-caused deforestation) of that area during all over Middle and Late Holocene. The maximum percentages and PARs for North-West European Russia (Polistovsky National Reserve - Nosova et al. 2017) and Central European Rus- sia (Central Forest Reserve - Novenko et al. 2009) are presented in the Table 1.

Extremely high PAR-values for Picea pollen were recorded in Middle and Late Holocene and then there was relatively late decline of primary forests. Thus, the challenge in search of modern analogues and examination of possible threshold values for the presence or absence of spruce trees in vegetation has been raised.

\section{Study area}

This study presents 9-year results of modern pollen data obtained from 23 Tauber pollen traps, operating in frame 


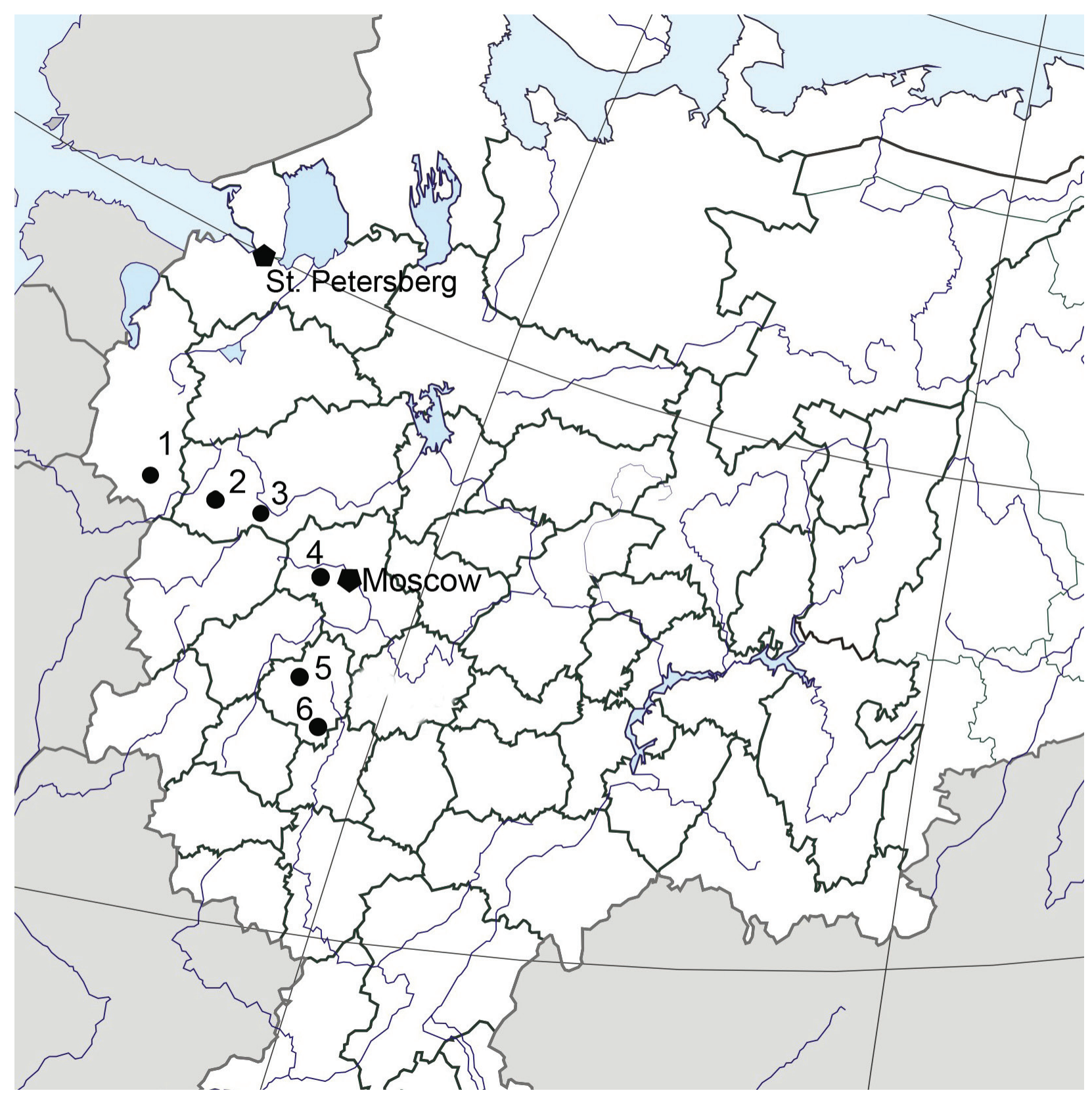

Figure 1. PMP-sites within the European part of Russia

of the Pollen Monitoring Programme (Hicks et al. 1996; www.pollentrapping.org), located on 6 model territories in 4 regions in the European part of Russia (Fig. 1):

1. RU-PL - Polistovsky Natural Reserve (northwestern European Russia, Pskov Region, coniferousbroadleaved forest zone). 2. RU-TR - Biological Station "Chisty Les" (Tver region, sand-soil type of coniferous-broadleaved forest zone) 3. RU-CF - Central Forest State Natural Biosphere Reserve (Tver Region, south slope of Valdai Hills, taiga-faced, low disturbed forests in the coniferous-broadleaved forest zone. 4. RUZV - Zvenigorod Biological Station of Moscow State University (Moscow Region, south variant of coniferousbroadleaved forests located in the suburban belt of Moscow). 5. RU-TU - Tulskie Zaseki (surroundings of Tula town, broadleaved forest zone). 6. RU-KP - Military History and Natural Reserve "Kulikovo Field" (Tula region, forest-steppe ecotone). 
Vegetation maps based on satellite images were created for all territories within a $5 \mathrm{~km}$ radius from the trap locations. In addition, data from forest surveys were used for the interpretation of remote sensing data.

\section{Results and conclusions}

Preliminary results indicate the absence of appropriate modern analogues for primary forests among the investi- gated sites as vegetation and landscapes of all these regions has been transformed by humans significantly with maximum of deforestation in $1700^{\text {th }}-1900^{\text {th }}$.

Broadleaved trees PARs and percentages (Figure 2, Table 2) increase from the north to the south right up to broadleaved forest belt and then decrease in the foreststeppe ecotone. The lower values observed for the sites RU-TR (there are sand soils and a lot of Pinus) and RUCF (that site controlled by specifically cold microclimatic conditions).

Table 1. Maximum fossil pollen percentages and PARs (pollen grains $\mathrm{yrs}^{-1 *} \mathrm{~cm}^{-2}$ ) for two sites in the European Russia.

\begin{tabular}{|l|c|c|c|c|c|c|c|c|c|c|}
\hline \multicolumn{1}{|c|}{ Site/Region } & \multicolumn{2}{|c|}{ Picea } & \multicolumn{2}{c|}{ Quercus } & \multicolumn{2}{c|}{ Tilia } & \multicolumn{2}{c|}{ Ulmus } & \multicolumn{2}{c|}{ Fraxinus } \\
\cline { 2 - 11 } & $\%$ & PAR & $\%$ & PAR & $\%$ & PAR & $\%$ & PAR & \% & PAR \\
\hline $\begin{array}{l}\text { Polistovsky National } \\
\text { Reserve (Nosova et al., } \\
\text { in press) }\end{array}$ & 25 & 56000 & 11.9 & 8500 & 4.7 & 6300 & 13.5 & 24000 & 4.2 & 2700 \\
\hline $\begin{array}{l}\text { Central Forest Reserve } \\
\text { (Novenko et al., 2009) }\end{array}$ & 40 & 47000 & 5.7 & 3500 & 4.8 & 9500 & 11 & 13000 & 1.6 & 2300 \\
\hline
\end{tabular}

Picea and broadleaved trees show maximum modern PARs $\sim 10$ times less than the fossil PARs (Table 1).

Table 2. Average PAR-values (pollen grains $* \mathrm{yrs}^{-1 *} \mathrm{~cm}^{-2}$ ) and pollen percentages (based on total terrestrial pollen sum - P) for six trap-sites in European Russia.

\begin{tabular}{|c|c|c|c|c|c|c|c|}
\hline \multicolumn{2}{|c|}{ Site/Region--> } & RU-PL & RU-TR & RU-CF & RU-ZV & RU-TU & RU-KP \\
\hline \multirow{2}{*}{ Picea } & PAR & 897 & 934 & 690 & 2075 & 120 & 80 \\
\hline & $\%$ & 1.7 & 2.1 & 1.7 & 3.5 & 0.2 & 0.3 \\
\hline \multirow{2}{*}{ Tilia } & PAR & 0 & 9 & 10 & 347 & 1622 & 61 \\
\hline & $\%$ & 0.0 & 0.0 & 0.0 & 1.0 & 1.7 & 0.2 \\
\hline \multirow{2}{*}{ Ulmus } & PAR & 209 & 159 & 66 & 827 & 279 & 50 \\
\hline & $\%$ & 0.3 & 0.5 & 0.2 & 0.5 & 0.8 & 0.1 \\
\hline \multirow{2}{*}{ Fraxinus } & PAR & 233 & 180 & 26 & 362 & 1058 & 125 \\
\hline & $\%$ & 0.1 & 0.5 & 0.1 & 0.3 & 1.7 & 0.4 \\
\hline \multirow{2}{*}{ Acer } & PAR & 42 & 1 & 16 & 24 & 550 & 151 \\
\hline & $\%$ & 0.1 & 0.0 & 0.1 & 0.0 & 0.7 & 0.3 \\
\hline \multirow{2}{*}{ Quercus } & PAR & 151 & 145 & 73 & 438 & 1345 & 251 \\
\hline & $\%$ & 0.2 & 0.4 & 0.2 & 0.5 & 1.6 & 0.7 \\
\hline \multirow{2}{*}{ Corylus } & PAR & 267 & 101 & 154 & 206 & 1060 & 108 \\
\hline & $\%$ & 0.5 & 0.4 & 0.6 & 0.4 & 1.7 & 0.3 \\
\hline
\end{tabular}




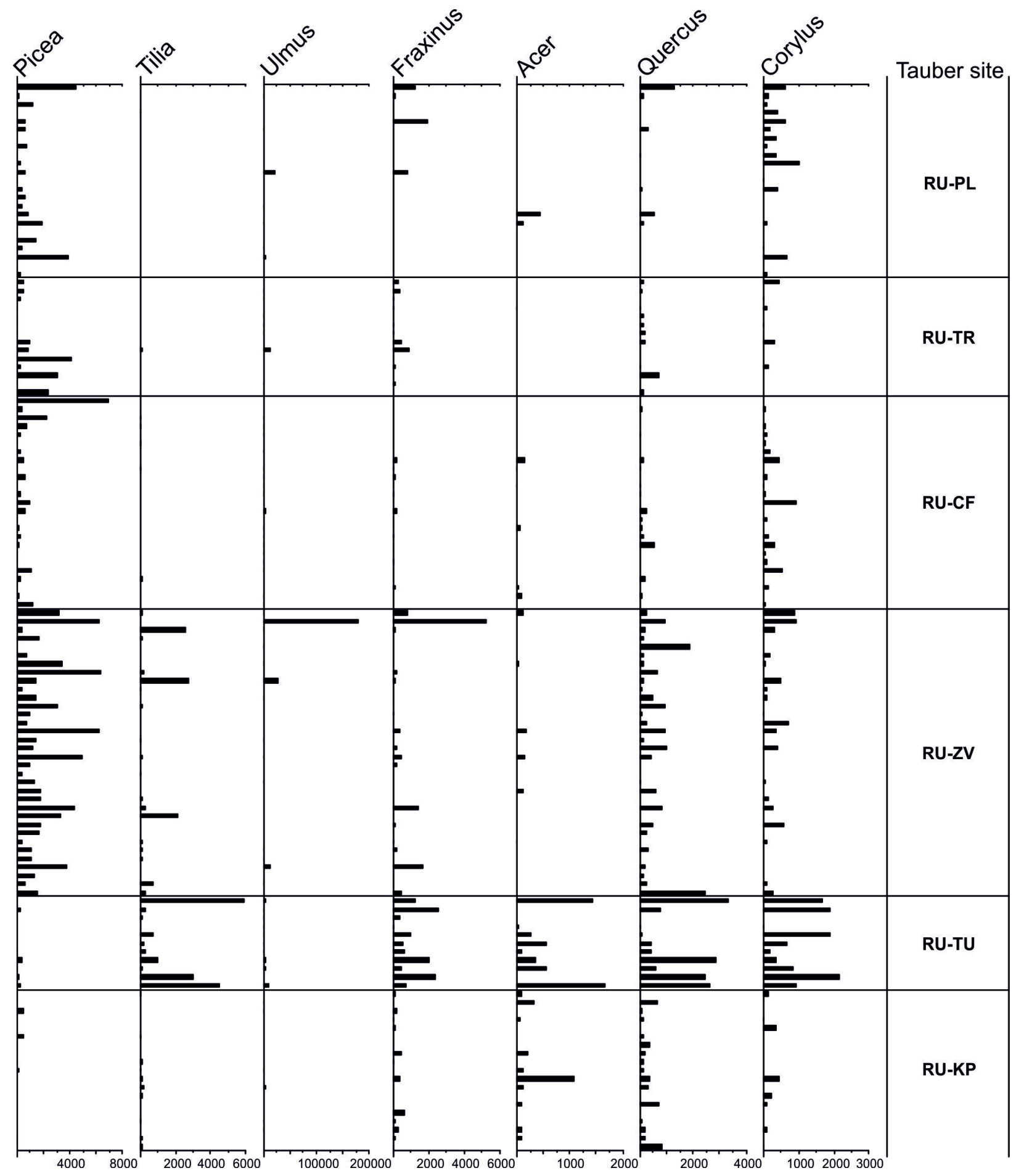

Figure 2. PAR diagram for 9 years of pollen monitoring (years are not specified, don't include the missed ones and increase from bottom to top)

We suggest to determine threshold values for Picea PAR $\sim 100$ p.g. $* \mathrm{yrs}^{-1 *} \mathrm{~cm}^{-2}$ and less than $1 \%$. For broadleaved trees (except Quercus) we support the opinion of many authors (e.g. Lisitsyna et al. 2011) that threshold values are $\sim 0,5 \%$ and suggest the $<50$ PAR as a criteria of absence or single trees of broadleaved species in the vegetation. 
Three zones investigated (south taiga, mixed coniferous-broadleaved forests and broadleaved forests) are well detected by Picea/broadleaved pollen ratio even in modern modified state of vegetation.

\section{Acknowledgements}

The study was supported by Russian Foundation for Basic Research (projects RFBR15-29-02486, 16-34-00804, 1704-01034)

\section{References}

Hicks S., Ammann B., Latałowa M. \& Pardoe H., 1996, European pollen monitoring programme, Project de- scription and guidelines, Oulu University Press, Oulu, Finland.

Lisitsyna O. V., Giesecke T., \& Hicks S., 2011, Exploring pollen percentage threshold values as an indication for the regional presence of major European trees, Review of Palaeobotany and Palynology 166(3): 311-324.

Nosova M.B., Severova E.E. \& Volkova O.A., 2017, A 6500-year pollen record from the Polistovo-Lovatskaya Mire System (North-West European Russia), Vegetation dynamics and signs of human impact, Grana in press.

Novenko E.Y., Volkova E.M., Nosova N.B. \& Zuganova I.S., 2009, Late Glacial and Holocene landscape dynamics in the southern taiga zone of East European Plain according to pollen and macrofossil records from the Central Forest State Reserve (Valdai Hills, Russia), Quaternary International 207: 93-103. 